\title{
Perbandingan Metode Perhitungan Evapotranspirasi Potensial di Paloh Kabupaten Sambas Kalimantan Barat
}

Andre Wilnaldo*, Yoga Satria Putra, Riza Adriat

\author{
Program Studi Geofisika, FMIPA Universitas Tanjungpura, Jl. Prof. Dr. Hadari Nawawi, Pontianak \\ *Email : awowilnaldo19@student.untan.ac.id
}

(Diterima 24 Juli 2020; Disetujui 12 Desember 2020; Dipublikasikan 14 Desember 2020)

\begin{abstract}
Abstrak
Laju evapotranspirasi yang terjadi dengan anggapan persediaan jumlah air dan kelembapan tanah cukup sepanjang tahun dikenal dengan istilah evapotranspirasi potensial. Metode David, Prescott, Stephen, Ivanov dan Penman adalah metode yang dapat digunakan untuk menganalisis evapotranspirasi potensial dan metode panci penguapan sebagai pembanding. Penelitian ini bertujuan untuk mengetahui metode empiris dengan nilai error terkecil dalam penentuan evapotranspirasi potensial di Paloh Kabupaten Sambas Kalimantan Barat. Data yang digunakan dalam penelitian ini adalah data sekunder bulanan dari tahun 2013-2017 yaitu evaporasi panci penguapan, suhu udara, kelelembapan relatif, durasi penyinaran matahari dan kecepatan angin. Berdasarkan hasil penelitian diperoleh metode dengan error terkecil adalah metode Ivanov sebesar 0,04 dan metode Penman memiliki nilai korelasi tertinggi sebesar 0,6.
\end{abstract}

Kata Kunci : Evapotranspirasi Potensial, Metode David, Metode Prescott, Metode Ivanov, Metode Penman

\section{Latar Belakang}

Kabupaten Sambas khususnya Kecamatan Paloh adalah salah satu daerah beriklim tropis yang berdekatan dengan garis lintang $0^{\circ}$ (garis khatulistiwa). Letak geografis tersebut mempengaruhi kondisi meteorologi di Paloh, terutama suhu udara dan kelembapan udaranya yang relatif tinggi [1] serta unsur-unsur cuacanya menjadi lebih kompleks, sehingga hal tersebut dapat menyebabkan kenaikan evapotranspirasi lebih besar. Besarnya evapotranspirasi di Kecamatan Paloh tentunya berbeda dibandingkan dengan wilayah yang letaknya jauh dari garis khatulistiwa [2].

Evapotranspirasi adalah gabungan dua proses dari siklus hidrologi yaitu evaporasi dan transpirasi. Evapotranspirasi potensial merupakan laju penguapan yang terjadi dengan anggapan persediaan air dan kelembapan tanah cukup sepanjang waktu. Evapotranspirasi potensial dapat dianalisis menggunakan beberapa rumus empiris dengan perhitungan berdasarkan data unsurunsur cuaca seperti suhu udara, kelembapan relatif, evaporasi, lamanya penyinaran matahari, dan kecepatan angin.

Erlisa (2009) telah meneliti tentang pengaruh unsur cuaca terhadap evapotranspirasi potensial di Kota Pontianak menggunakan data dari tahun 1984-2007. Dari penelitian tersebut diperoleh metode David dengan nilai error terkecil yaitu sebesar 0,043 [2]. Berlian (2010) juga telah meneliti tentang pengaruh pemanasan global terhadap metode yang paling sesuai untuk analisa evapotranspirasi potensial menggunakan data harian stasiun BMKG Supadio. Berlian menyimpulkan bahwa metode yang sesuai untuk analisa evapotranspirasi potensial di kota Pontianak dan sekitarnya berdasarkan data klimatologi harian stasiun BMKG Supadio adalah metode David dengan presentase kesalahan relatif sebesar 41,29\% [3].

Penelitian ini dilakukan untuk memperkirakan nilai evapotranspirasi potensial di Kecamatan Paloh berdasarkan data unsur cuaca yang diperoleh dari Stasiun BMKG Paloh. Tujuan dari penelitian adalah untuk menganalisis perhitungan evapotranspirasi potensial di Paloh menggunakan beberapa metode empiris. Uji nilai korelasi dan error antara evapotranspirasi potensial berdasarkan data pengamatan panci penguapan terhadap evapotranspirasi potensial menggunakan metode empiris akan dilakukan dalam penelitian ini. Hasil penelitian ini diharapkan dapat memberikan informasi mengenai metode empiris dengan nilai error terkecil yang dapat dijadikan sebagai dasar pertimbangan untuk memperkirakan evapotranspirasi potensial $\mathrm{di}$ Paloh Kabupaten Sambas Kalimantan Barat. 


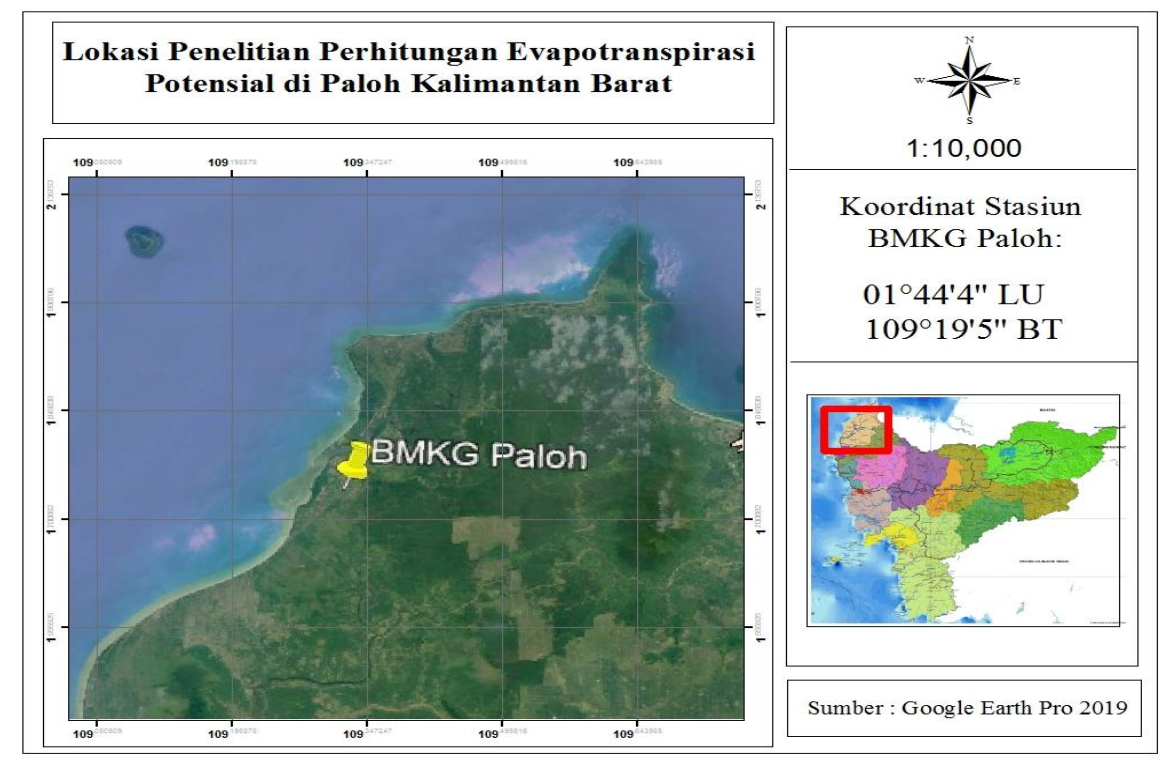

Gambar 1. Lokasi Stasiun BMKG Paloh, (Sumber Google Earth 2019)

\section{Metodologi}

Daerah kajian penelitian ini ditunjukkan pada Gambar 1, yaitu di Paloh Kabupaten Sambas Kalimantan Barat dengan menggunakan data unsur cuaca bulanan dari tahun 2013-2017 yang diperoleh dari Stasiun BMKG Paloh yang terletak pada garis lintang $01^{\circ} 44^{\prime} 4$ " LU dan 109 $19^{\prime} 5^{\prime \prime}$ BT.Data yang digunakan untuk menghitung evapotranspirasi potensial berupa data sekunder selama 5 tahun, yaitu suhu udara, kelembapan relatif, lamanya penyinaran matahari, kecepatan angin dan evaporasi dari panci penguapan. Berikut ini adalah metode-metode yang digunakan untuk menghitung evapotranspirasi potensial di Paloh:

\section{A. Metode Panci Penguapan}

Menghitung evapotranspirasi potensial menggunakan data evaporasi dari panci penguapan kelas A, data evaporasi dari panci penguapan harus dikalikan dengan nilai koefisien panci (Kp). Berikut ini merupakan persamaan yang digunakan [4]:

$$
\begin{aligned}
& \text { ETo }=\text { Kp } \times \text { Ep } \\
& \begin{aligned}
\mathrm{Kp}= & 0,475-\left(0,24 \times 10^{-3}\right)\left(\mathrm{U}_{2 \mathrm{~m}}\right)+0,00516 \\
& \left(\mathrm{RH}_{\text {mean }}\right)+0,00118(\mathrm{~d})-\left(0,16 \times 10^{-4}\right) \\
& \left(\mathrm{RH}_{\text {mean }}\right)^{2}-\left(0,101 \times 10^{-5}\right)(\mathrm{d})^{2}-0,8 \times 10^{-8} \\
& \left(\mathrm{RH}_{\text {mean }}\right)^{2}\left(\mathrm{U}_{2 \mathrm{~m}}\right)-1 \times 10^{-8}\left(\mathrm{RH}_{\text {mean }}\right)^{2} \cdot(\mathrm{d})
\end{aligned}
\end{aligned}
$$

keterangan:

ETo : evapotranspirasi potensial (mm/hari)

Kp : koefisien panci penguapan

Ep : evaporasi dari panci (mm/hari)

$\mathrm{U}_{2 \mathrm{~m}} \quad$ : kecepatan angin ketinggian 2 meter (m/hari)

$\mathrm{RH}_{\text {mean }}$ : kelembapan relatif (\%)

d : jarak dari panci ke vegetasi sekitar panci 2 meter $(\mathrm{m})$

$\mathrm{U}_{\mathrm{z}} \quad$ : kecepatan angin pada ketinggian $\mathrm{z}(\mathrm{m})$

$\mathrm{z} \quad$ : ketinggian alat ukur kecepatan angin (m)

\section{B. Metode David}

Pada tahun 1936 David memperkirakan evapotranspirasi potensial menggunakan data suhu udara dan kelembapan relatif dengan Persamaan [4]:

ETo $=0,50\left(\mathrm{e}_{\mathrm{s}}-\mathrm{e}_{\mathrm{d}}\right)$

$\mathrm{e}_{\mathrm{d}}=\mathrm{e}_{\mathrm{s}} \times \mathrm{RH}$

keterangan:

$\mathrm{e}_{\mathrm{s}} \quad$ : tekanan uap jenuh pada suhu udara tertentu (mbar)

$e_{d}$ :tekanan uap pada titik embun dengan kelembapan relatif tertentu (mbar) 


\section{Metode Prescott}

Pada tahun 1949 Prescott menentukan evapotranspirasi potensial dengan dengan data suhu udara dan kelembapan relatif [5] menggunakan Persamaan [4]:

$E T o=\left(\mathrm{e}_{\mathrm{s}}-\mathrm{e}_{\mathrm{d}}\right)^{0,75}$

\section{Metode Stephen}

Menggunakan metode radiasi global $\left(\mathrm{R}_{s} \cdot \mathrm{Kal} / \mathrm{cm}^{2} /\right.$ hari) dan data suhu udara bulanan rata-rata $\left({ }^{\circ} \mathrm{C} /\right.$ bulan $)$, maka dapat diperkirakan evapotranspirasi potensial dengan metode Stephen [6]. Persamaan empiris untuk metode ini adalah [3]:

ETo $=(0,0014 \mathrm{~T}-0,37) \frac{\mathrm{R}_{\mathrm{S}}}{1500}$

$\mathrm{R}_{\mathrm{s}}=\mathrm{R}_{\mathrm{a}}\left[0,25+0,50\left(\frac{\mathrm{n}}{\mathrm{N}}\right)\right]$

keterangan:

ETo : evapotranspirasi potensial (mm/hari)

$\mathrm{T}$ : suhu udara bulanan rata-rata $\left({ }^{\circ} \mathrm{C}\right)$

$\mathrm{R}_{\mathrm{s}} \quad$ : radiasi global $\left(\mathrm{Kal} / \mathrm{cm}^{2} /\right.$ hari)

$\mathrm{R}_{\mathrm{a}} \quad$ : radiasi berdasarkan lintang $\left(\mathrm{Kal} / \mathrm{cm}^{2} /\right.$ hari)

$\mathrm{n} / \mathrm{N} \quad$ : durasi penyinaran matahari relatif (\%)

\section{E. Metode Penman (1948)}

Metode Penman merupakan metode yang dikembangkan di Inggris bagian selatan dan sering digunakan di Indonesia tanpa penyesuaian [4]. Penman memperkirakan evapotranspirasi potensial dengan mengombinasikan data kelembapan relatif $(\mathrm{RH})$, lamanya penyinaran matahari (n/N), suhu udara (T) dan kecepatan angin (U) menggunakan Persamaan [7]:

$$
\begin{aligned}
\text { ETo }= & {\left[\delta /(\delta+\tau) \times \mathrm{R}_{\mathrm{n}}+\tau /(\delta+\tau)\right] \times } \\
& {\left[0,35\left(1,0+0,009 \mathrm{U}_{2}\right)\left(\mathrm{e}_{\mathrm{s}}-\mathrm{e}_{\mathrm{a}}\right)\right] }
\end{aligned}
$$

Nilai $\mathrm{R}_{\mathrm{n}}$, dihitung dengan rumus:

$R_{n}=R_{s}(1-\alpha)-R_{b}$

Maka nilai:

$$
\mathrm{U}_{2}=\mathrm{U}_{\mathrm{h}} \times \frac{\log 10}{\left[\frac{\log 10 \mathrm{~h}}{2}\right]}
$$

$$
\begin{aligned}
\mathrm{e}_{\mathrm{s}}= & 0,611 \exp \left[\frac{17,27 \mathrm{~T}}{\mathrm{~T}+237,3}\right] \\
\mathrm{e}_{\mathrm{a}}= & \mathrm{e}_{\mathrm{s}} \times \mathrm{RH} \\
\delta= & \frac{4089 \times \mathrm{e}_{\mathrm{a}}}{(\mathrm{T}+237,3)^{2}} \\
\mathrm{R}_{\mathrm{b}}= & \left(\beta \times \mathrm{T}_{\mathrm{k}}^{4}\right) \times\left[0,34-0,14\left(\mathrm{e}_{\mathrm{a}}\right)^{\left(\frac{1}{2}\right)}\right] \\
& {[0,10+0,90(\mathrm{n} / \mathrm{N})] } \\
\mathrm{R}_{\mathrm{s}}= & \mathrm{R}_{\mathrm{a}}[0,25+0,50(\mathrm{n} / \mathrm{N})]
\end{aligned}
$$

keterangan:

ETo : Evapotranspirasi potensial (mm/hari)

$\delta \quad:$ Kemiringan kurva tekanan uap terhadap temperatur $\left(\mathrm{mbar} /{ }^{\circ} \mathrm{C}\right)$

$\tau \quad$ : Konstanta psikrometrik $=0,006466$ mbar $/{ }^{\circ} \mathrm{C}$

$\mathrm{R}_{\mathrm{n}} \quad$ : Radiasi bersih (mm/hari)

$\mathrm{U}_{2} \quad$ : Kecepatan angin pada tinggi 2 meter (mile/hari)

$\mathrm{e}_{\mathrm{a}} \quad$ : tekanan uap aktual (mbar)

$\mathrm{e}_{\mathrm{s}} \quad$ : tekanan uap jenuh (mbar)

$\mathrm{RH} \quad$ : Kelembapan relatif (\%)

$\mathrm{R}_{\mathrm{s}} \quad$ : Radiasi global (mm/hari)

$\mathrm{R}_{\mathrm{b}} \quad$ :Radiasi gelombang panjang yang kembali ke atmosfer ( $\mathrm{mm} /$ hari)

$\mathrm{R}_{\mathrm{a}} \quad$ : Radiasi ekstra teresterial (mm/hari)

$\alpha \quad$ : Albedo (untuk tanaman rujukan 23\%)

$\mathrm{n} / \mathrm{N} \quad$ : Durasi penyinaran matahari relatif (\%)

$\beta \quad$ : Konstanta Stephan-Boltzmann yaitu $2,01 \times 10^{-9}$ (mm/hari)

$\mathrm{T}_{\mathrm{k}} \quad$ : Suhu udara $\left({ }^{\circ} \mathrm{K}\right),\left({ }^{\circ} \mathrm{K}=273+{ }^{\circ} \mathrm{C}\right)$

\section{F. Metode Ivanov}

Pada tahun 1959 Ivanov memperkirakan evapotranspirasi potensial di danau Franklin Playa berbasis data suhu udara dan kelembapan relatif [8]. Persamaan empiris untuk metode Ivanov adalah [4]:

ETo $=0,0018\left[\left(25+\mathrm{T}^{2}\right)(100-\mathrm{RH})\right]$

Keterangan:

$\mathrm{T} \quad$ : suhu bulanan rata-rata $\left({ }^{0} \mathrm{C} /\right.$ bulan $)$

$\mathrm{RH} \quad$ : kelembapan relatif (\%)

\section{G. Uji Korelasi}

Analsis korelasi dalam penelitian ini digunakan untuk mengetahui keeratan hubungan antara evapotranspirasi potensial berdasarkan 
metode panci penguapan dengan evapotranspirasi potensial berdasarkan unsur cuaca dengan metode empiris. Persamaan korelasi yang digunakan dalam penelitian ini [9]:

$\mathrm{r}=\frac{\mathrm{n} \sum \mathrm{x}_{\mathrm{i}} \mathrm{y}_{\mathrm{i}}-\left(\sum \mathrm{x}_{\mathrm{i}}\right)\left(\sum \mathrm{y}_{\mathrm{i}}\right)}{\sqrt{\left(\mathrm{n} \sum \mathrm{x}_{\mathrm{i}}^{2}-\left(\sum \mathrm{x}_{\mathrm{i}}\right)^{2}\right)\left(\mathrm{n} \sum \mathrm{y}_{\mathrm{i}}^{2}-\left(\sum \mathrm{y}_{\mathrm{i}}\right)^{2}\right)}}$

keterangan:

r : korelasi

$x_{i} \quad$ : evapotranspirasi potensial dari metode empiris

$y_{i} \quad$ : evapotranspirasi potensial dari panci penguapan

n : Jumlah data

\section{H. Root Mean Square Error (RMSE)}

Analsis RMSE dalam penelitian ini digunakan untuk mengetahui tingkat kesalahan antara evapotranspirasi potensial berdasarkan metode panci penguapan terhadap evapotranspirasi potensial berdasarkan unsur cuaca dengan metode empiris. Berikut adalah persamaan RMSE yang digunakan dalam penelitian ini [10]:
$\mathrm{RMSE}=\sqrt{\frac{1}{\mathrm{n}} \sum_{\mathrm{i}=1}^{\mathrm{n}}\left(\text { ETo }_{\text {panci penguapan }}-E T o_{\text {metode }}\right)^{2}}$

keterangan:

$E T o_{\text {panci penguapan }}$ : evapotranspirasi potensial dengan panci penguapan

$E T o_{\text {metode }} \quad$ : evapotranspirasi potensial dengan metode empiris

$\mathrm{n}$ : jumlah data

\section{Hasil dan Pembahasan}

\subsection{Analisis Evapotranspirasi Potensial}

Hasil analisis Pada Tabel 1, diperlihatkan bahwa evapotranspirasi potensial rata-rata bulanan di Paloh dari tahun 2013-2017 sebesar 1,91 mm/hari. Besarnya evapotranspirasi potensial rata-rata bulanan berdasarkan unsur cuaca menggunakan beberapa metode empiris, yaitu metode David $2,86 \mathrm{~mm} / \mathrm{hari}$, metode Prescott 3,68 mm/hari, metode Stephen 5,71 $\mathrm{mm}$ /hari, metode Penman 2,11 $\mathrm{mm} /$ hari dan metode Ivanov 2,41 mm/hari. Tabel berikut adalah evapotranspirasi potensial rata-rata bulanan di Paloh dari tahun 2013-2017:

Tabel 1. Perbandingan evapotranspirasi rata-rata bulanan (mm/hari) Tahun 2013-2017.

\begin{tabular}{|c|c|c|c|c|c|c|}
\hline Bulan & Panci Penguapan & Metode David & $\begin{array}{l}\text { Metode } \\
\text { Prescott }\end{array}$ & $\begin{array}{l}\text { Metode } \\
\text { Stephen }\end{array}$ & $\begin{array}{l}\text { Metode } \\
\text { Penman }\end{array}$ & $\begin{array}{l}\text { Metode } \\
\text { Ivanov }\end{array}$ \\
\hline & 1,73 & 2,18 & 3,01 & 5,04 & 1,649 & 1,84 \\
\hline & 1,63 & 2,12 & 2,94 & 5,29 & 1,88 & 1,96 \\
\hline Feb & & & & & & \\
\hline & 2,06 & 2,56 & 3,40 & 6,04 & 2,58 & 2,14 \\
\hline Mar & 204 & 296 & 378 & 677 & 279 & 251 \\
\hline Apr & 2,04 & 2,96 & $3, / 8$ & $6, / 7$ & $2, / 9$ & 2,51 \\
\hline & 2 & 3,18 & 4,001 & 6,04 & 2,19 & 2,60 \\
\hline Mei & 1,89 & 3,24 & 4,06 & 5,8 & 2,21 & 2,74 \\
\hline Juni & & & & & & \\
\hline & 1,98 & 3,63 & 4,41 & 6,31 & 2,30 & 2,96 \\
\hline Juli & 2,15 & 3,36 & 4,16 & 5,84 & 2,24 & 2,78 \\
\hline Agus & 2,02 & 3,12 & 3,94 & 5,7 & 2,11 & 2,68 \\
\hline Sep & & & & & & \\
\hline & 2,05 & 2,96 & 3,78 & 5,72 & 2,13 & 2,45 \\
\hline Okt & 1,68 & 2,59 & 3,40 & 5,08 & 1,77 & 2,23 \\
\hline Nov & & & & & & \\
\hline Des & 1,71 & 2,43 & 3,25 & 4,86 & 1,45 & 2,04 \\
\hline Rata-rata & 1,91 & 2,86 & 3,68 & 5,71 & 2,11 & 2,41 \\
\hline
\end{tabular}




\subsection{Analisis Nilai Korelasi dan RMSE Evapotranspirasi Potensial}

Pada Gambar 2, menyajikan grafik hasil perhitungan evapotranspirasi potensial bulanan tahun 2013-2017 di Paloh. Dari grafik tersebut memperlihatkan bahwa masing-masing metode menghasilkan besaran evapotranspirasi potensial yang berbeda. Evapotranspirasi potensial yang berbeda-beda ini disebabkan karena adanya pengaruh perbedaan musim, parameter unsur cuaca yang digunakan, serta faktor penyesuaian, konversi, dan koreksi yang ditetapkan oleh metode tersebut. Berdasarkan hal tersebut maka perhitungan korelasi dan nilai error evapotranspirasi potensial menggunakan data bulanan dari tahun 2013-2017.

Hasil perhitungan evapotranspirasi potensial yang disajikan Tabel 2, memperlihatkan bahwa metode dengan error terkecil adalah metode Ivanov yaitu sebesar 0,04 , namun dengan korelasi yang paling rendah dari metode lain yaitu sebesar
0,34. Metode David memiliki korelasi 0,37 dengan error sebesar 0,12 dan untuk metode Prescott memiliki korelasi 0,38 serta error sebesar 0,27. Evapotranspirasi potensial dengan metode David, metode Prescott dan metode Ivanov termasuk pada interval korelasi rendah, hal tersebut disebabkan oleh parameter suhu udara dan kelembapan relatif yang digunakan dalam perhitungan sehingga mempengaruhi korelasi dan nilai error yang diperoleh. Suhu udara memiliki hubungan yang berbanding lurus terhadap evapotranspirasi potensial, apabila suhu udara naik maka evapotranspirasi potensial akan meningkat. Kelembapan relatif memiliki hubungan yang berbanding terbalik terhadap evapotranspirasi potensial, ketika kelembapan relatif meningkat maka evapotranspirasi potensial akan menurun. Berikut ini adalah tabel hasil perhitungan evapotranspirasi potensial dari beberapa metode di Stasiun BMKG Paloh tahun 2013-2017:

Tabel 2. Hasil perhitungan evapotranspirasi potensial (ETo) dengan beberapa metode di Stasiun BMKG Paloh tahun 2013-2017.

\begin{tabular}{|c|c|c|c|c|c|}
\hline No & Metode & Parameter & $\begin{array}{l}\text { Nilai rata-rata ETo } \\
2013-2017 \\
\text { (mm/hari) }\end{array}$ & Korelasi & RMSE \\
\hline \multirow[t]{2}{*}{1} & Panci & $\begin{array}{l}\text { Kecepatan Angin } \\
\text { (Knot) }\end{array}$ & & & \\
\hline & Penguapan & $\begin{array}{l}\text { Kelembapan relatif } \\
(\%)\end{array}$ & 1,91 & - & - \\
\hline 2 & David & Suhu Udara $\left({ }^{0} \mathrm{C}\right)$ & 2,86 & 0,37 & 0,12 \\
\hline 3 & Prescott & $\begin{array}{l}\text { Kelembapan relatif } \\
(\%)\end{array}$ & 3,68 & 0,38 & 0,27 \\
\hline 4 & Ivanov & $\begin{array}{l}\text { Suhu Udara }\left({ }^{\circ} \mathrm{C}\right) \\
\text { Kelembapan relatif } \\
(\%)\end{array}$ & 2,41 & 0,34 & 0,04 \\
\hline 5 & Penman & $\begin{array}{l}\text { Kecepatan Angin } \\
\text { (Knot) } \\
\text { Durasi Penyinaran } \\
\text { Mathari (\%) }\end{array}$ & 2,11 & 0,6 & 0,08 \\
\hline 6 & Stephen & $\begin{array}{l}\text { Suhu Udara }\left({ }^{0} \mathrm{C}\right) \\
\text { Durasi Penyinaran } \\
\text { Matahari }(\%)\end{array}$ & 5,71 & 0,53 & 0,59 \\
\hline
\end{tabular}




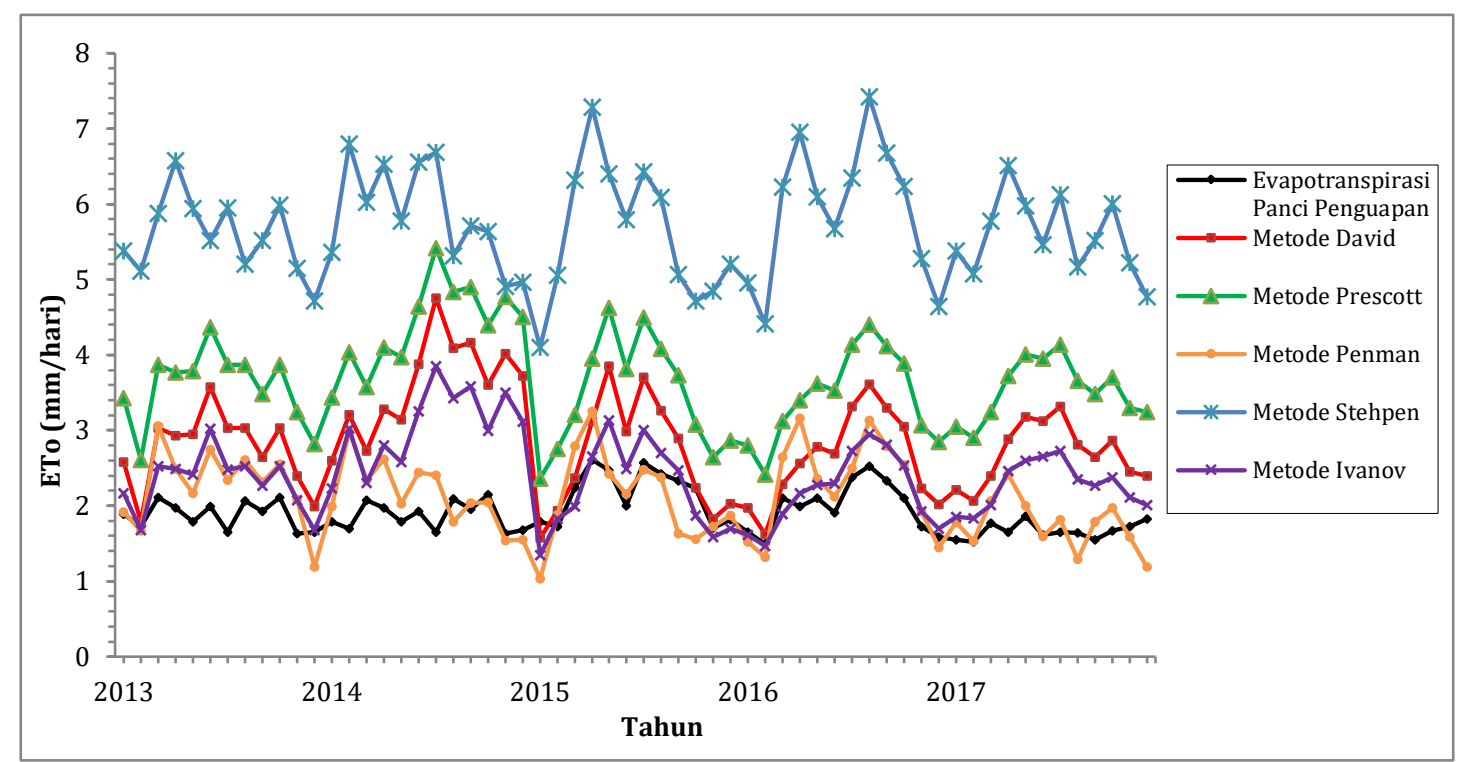

Gambar 2. Grafik perbandingan evapotranspirasi potensial bulanan dari Tahun 2013-2017 di Paloh

Metode dengan error terbesar diantara metode perhitungan lainnya adalah metode Stephen yaitu dengan error sebesar 0,59 dan memiliki korelasi 0,53 artinya termasuk korelasi sedang. Jarak kurva antara evapotranspirasi potensial sebenarnya terhadap evapotranspirasi potensial dengan metode Stephen pada Gambar 2, memperlihatkan jarak yang paling jauh dari metode lain. Penggunaan parameter suhu udara dan durasi penyinaran matahari diduga menyebabkan kenaikan evapotranspirasi potensial yang besar, serta memiliki hubungan berbanding lurus terhadap evapotranspirasi potensial. Semakin besar penyinaran matahari maka suhu udara akan naik sehingga evapotranspirasi potensial juga akan ikut meningkat.

Metode Penman memiliki korelasi 0,6 artinya memiliki hubungan yang kuat dengan evapotranspirasi panci penguapan dan memperoleh error sebesar 0,08. Dari Gambar 2 terlihat bahwa jarak kurva nilai evapotraspirasi potensial menggunakan metode Penman paling mendekati evapotranspirasi potensial sebenarnya. Input parameter dan jumlah data yang digunakan dalam perhitungan evapotranspirasi potensial untuk metode Penman lebih banyak dibandingkan dengan metode lain, yaitu menggunakan suhu udara, kelembapan relatif, kecepatan angin, dan lamanya penyinaran matahari. Saat penyinaran matahari, suhu udara dan kecepataan angin meningkat serta kelembapan relatif rendah, maka evapotranspirasi potensial akan meningkat.

\section{Kesimpulan}

a. Nilai rata-rata evapotranspirasi potensial berdasarkan panci penguapan di Stasiun BMKG Paloh tahun 2013-2017 sebesar 1,91 $\mathrm{mm} / \mathrm{hari}$.

b. Nilai error setiap metode adalah: metode David $(0,12)$ metode Prescott $(0,27)$, metode Stephen $(0,59)$; metode Penman $(0,08)$; dan metode Ivanov adalah metode dengan nilai error terkecil $(0,04)$.

c. Nilai korelasi yang diperoleh setiap metode adalah: metode David ( $\mathrm{r}=0,37)$; metode Prescott $(r=0,38)$; metode Stephen $(r=0,53)$; metode Ivanov $(r=0,34)$; dan metode Penman adalah metode dengan nilai korelasi tertinggi $(r=0,6)$.

d. Penggunaan suhu udara, durasi penyinaran matahari dan kecepatan angin pada perhitungan evapotranspirasi potensial menghasilkan nilai korelasi yang tinggi.

e. Kelembapan relatif memiliki hubungan yang berbanding terbalik terhadap evapotranspirasi potensial, saat kelembapan relatif rendah. 


\section{Daftar Pustaka}

[1] Ihwan, A., Analisis Tingkat Kekeringan Menggunakan Parameter Cuaca di Kota Pontianak dan Sekitarnya, PRISMA FISIKA, Vol. 1, No 2(2337-8204), 75-81, 2013.

[2] Erlisa, Pengaruh Unsur Cuaca Terhadap Evapotranspirasi Potensial Di Kota Pontianak, Universitas Tanjungpura Pontianak, Pontianak, 2009.

[3] Berlian, S., Pengaruh Pemanasan Global Terhadap Metoda Yang Paling Sesuai Untuk Analisa Evapotranspirasi Potensial Berdasarkan Data Harian Stasiun Bmg Supadio, Universitas Tanjungpura Pontianak, Pontianak, 2010.

[4] Soewarno, Seri Hidrologi Klimatologi, Yogyakarta, Graha Ilmu, 2015.

[5] Prescott, J., Climatic Index or The Leaching Factor In Soil Formation, Journal Soil Sci, 751787, 1949.

[6] Stephen, J., A Comparison of Procedures for Computing Evaporation and Evapotranspiration, International Association of Scientific Hydrology, 123- 133, 1963.

[7] Penman, H., Natural Evaporation From Open Water, Bare Soil, and Grass, Proc. Royal Soc, 120-146, 1948.

[8] Ivanov, The Determination of Potential Evapotranspiration, Izvestiia Vsesoiuznogo Geograficheskogo Obschestva, 86, 1959.

[9] Mattjik, A. A., \& Sumertajaya, I. M, Perancangan Percobaan dengan Aplikasi SAS Dan Minitab Jilid I, IPB Press, 2000.

[10] Makridakis, The Accuracy of Extrapolative (Time Series Methods): Results of a Forecasting Competition, Journal of Forecasting, Vol.1, 111-154, 1982. 